\title{
Canciones e interacciones en educación inicial
}

Song and interaction in early childhood education

Luzmila Mendivil Trelles de Peña* Imendiv@pucp.edu.pe 


\section{Resumen}

El presente artículo analiza resultados parciales de una investigación doctoral realizada en una institución educativa pública de educación inicial seleccionada al azar. El estudio muestra la dinámica de las interacciones que rodean a la canción infantil al interior de las aulas. La data se obtuvo mediante observaciones de jornadas completas en todas las aulas. El trabajo de campo se desarrolló en diversos meses a fin de no atribuir los resultados a eventos de la calendarización escolar. El estudio revela el impacto de las canciones en la constitución identitaria de los niños y de las propias docentes. Asimismo, contribuye a develar el rol de las canciones como discursos sociales que pueden producir efectos perversos como mecanismo de control y pone en evidencia la dinámica del poder docente.

Palavras-chave: Educación inicial, canciones, análisis crítico del discurso, interacción en aula.

\section{Abstract}

This article analyses partial results of doctoral research developed in an early childhood public center selected by random sampling. The study shows the dynamics of interactions involved in classroom singing. The data was collected through observation of classroom routines. The fieldwork was developed in different months in order to avoid associating the results with events in the academic calendar. This study reveals the impact of songs and singing on the children's and instructors' own identities. The study also helps illustrate the role of song as social discourse, producing perverse effects if used as a control mechanism, and clearly showing the dynamics of the teachers' power.

Keywords: Early childhood education, songs, critical discourse analysis interaction in classes. 


\section{Introducción: La pedagogía crítica como punto de partida}

La lectura de los hechos educativos desde el paradigma crítico es compleja, y por tanto demanda una mirada interdisciplinar.

Tal como sostienen diversos autores críticos tales como Freire (1971); Kincheloe (2008); Mc Laren (1998) la educación no es un proceso neutral en tanto de manera implícita o explícita persigue fines políticos que resultan inseparables de los fines pedagógicos. Como resultado, el aula de clases, las instituciones escolares, el proceso de escolarización, los medios y materiales educativos, la didáctica, la función y comprensión de los agentes educativos en los sistemas escolares, la formación docente, el rol del profesional de la educación, las políticas educativas, las interacciones, los ámbitos de aprendizaje, entre otros componentes del sistema educativo, son espacios imbuidos de carga ideológica. De allí la necesidad de analizar las interacciones y discursos que median el uso de los recursos en el contexto educativo y los aprendizajes o construcciones sociales explícitos o implícitos.

El enfoque crítico supera una concepción unidireccional y neutral de la educación y sus prácticas, y se orienta hacia una comprensión más integral, donde el campo de lo social, lo cultural, lo ético, lo político, y lo económico, son aspectos que se imbrican mutuamente y que ayudan a la comprensión de los procesos educativos al interior de los sistemas sociales.

Giroux (2008); Steinberg (2008); y Kincheloe (2008) coinciden al sostener que la pedagogía crítica trabaja por concretar la democracia como posibilidad social constituyéndose como "el espacio que proporciona una referencia moral y política para comprender de qué modo está relacionado lo que hacemos en las aulas con fuerzas más extensas de distinto tipo, ya sean sociales, políticas o económicas" (GIROUX, 2008, p. 20). En este sentido, su influencia se proyecta hacia la construcción de un futuro democrático y un orden social más justo.

La pedagogía crítica no admite separaciones entre las prácticas educativas y el sistema macro social. El trabajo académico entonces, necesariamente aborda asuntos fundamentales como democracia, autonomía, libertad, ideología y poder, lo que nos remite al estudio de la sociedad como un todo, entendida desde la centralidad del hombre y el desarrollo de todas sus potencialidades, y el comportamiento crítico de quien la lleva a cabo. En esta medida, no existe crítica, sin libertad, ni sin racionalidad crítica. La razón crítica es la clave para la liberación "Freedom is the result of the right action of reason. Rationality is substantive, not merely formal"1 (REGELSKI, 2005, p. 14). Conforme lo sostiene Kertz-Welzel (2011) la razón crítica representa la puerta de acceso a un nuevo reino de libertad en el que el campo de las ideas, se vincula con la realidad.

Del mismo modo, la pedagogía crítica analiza la función de la ideología, la que usualmente opera a favor de los grupos hegemónicos de la sociedad, y se concreta en cada momento de la acción educativa. En este sentido, los docentes no solo requieren 
de una formación académico profesional, sino ante todo demandan "claridad política e ideológica" (BARTOLOMÉ, 2008, p. 358) a fin de evitar legitimar un estatus quo que no responde a los propósitos de una educación democrática con calidad y equidad. A nivel político, la pedagogía crítica se orienta hacia la transformación de las estructuras de dominación.

A nivel ético, la pedagogía crítica representa una apuesta por el respeto a la persona, la afirmación de su libertad y de su capacidad para tomar decisiones sobre su propia vida. En esa medida demanda una clara conciencia de las realidades sociopolíticas y económicas que modelan sus condiciones reales de existencia, así como su capacidad de transformación.

Desde el paradigma crítico el docente no es un tecnólogo, técnico o científico aplicado, sino un intelectual transformador comprometido con la democracia y la consecución de un orden social más justo. La aspiración democrática, compromete la activa participación política de todos los agentes educativos en las diversas esferas de poder de la institución educativa: administrativos, docentes, estudiantes, autoridades. Como consecuencia, la teoría crítica busca la liberación de aquellas ideologías que impiden una visión y comprensión más amplia de la persona. La transformación social es un reto para la pedagogía crítica por tanto el papel de las instituciones educativas en la conformación de una sociedad democrática ocupa un lugar preponderante.

Las instituciones educativas en todos los niveles, comparten una responsabilidad política. Ellas están directamente vinculadas con la matriz social y cultural de la racionalidad hegemónica de diversas maneras. De un lado, habilitan a las diferentes clases y grupos sociales con el conocimiento necesario para ocupar lugares en una fuerza de trabajo estratificada y jerarquizada. Asimismo, a través de ellas se intercambian y legitiman formas de conocimiento, valores, lenguaje; se validan estilos de vida propios de la cultura dominante; cumpliendo así una función de reproducción cultural.

Un constructo teórico que establece una conexión ideológica entre las instituciones educativas y el sistema social es la noción de currículo oculto como "mensajes específicos que legitiman las visiones particulares de trabajo, autoridad, reglas sociales y valores que sostienen la lógica y la racionalidad capitalistas" (GIROUX, 1985, p. 8). Este es el medio de materialización de la ideología y se concreta en los ritos, rutinas y prácticas sociales y educativas que sustentan el trabajo diario de las escuelas (GIROUX, 1985).

De otro lado, los procesos de socialización en las instituciones educativas son holísticos e involucran dimensiones intelectuales, emocionales, sensoriales y físicas. Como resultado, el cuerpo como objeto de aprendizaje y control social se constituye como una dimensión de análisis del currículo oculto (GIROUX, 1985).

El lenguaje y los discursos es otro campo a los que presta atención la pedagogía crítica. La actividad pedagógica está imbuida de múltiples discursos, que crean, rechazan y justifican las diversas formas de ser y vivir de los diversos actores. La institución educativa como espacio político reproduce ciertos discursos legitimadores, mientras la escolaridad se concreta como una práctica "determinada y determinante" que se vincula con los procesos sociales más amplios (MC LAREN, 1998, p. 21).

El lenguaje y la adquisición de conocimiento en las instituciones educativas son 
construidos a través de prácticas habituales, "rituales" que reconocen la naturaleza multidimensional del ser humano y se influyen mutuamente. De ahí la necesidad de analizar el lenguaje propio de los procesos de aprendizaje cotidianos, y en el caso particular del presente estudio, de las canciones que son entonadas una y otra vez, así como de las interacciones alrededor de ella.

El lenguaje como referente básico de la existencia humana constituye un acto eminentemente social y político, e inevitablemente se vincula con las formas en que los individuos confieren sentidos y significados, su relación con el mundo y la propia construcción de las identidades. Por lo tanto, el lenguaje no es neutral, porque sus significados están influenciados por el contexto en el que se emplea. Las tensiones sociales se reflejan en el orden lingüístico por su relación con la dinámica autoral y con la voz (MC LAREN, 1998, p. 33). Su rol en la institución educativa está asociado a las posibilidades de subordinación o de resistencia. La palabra es estructurante en el conocimiento del mundo, por tanto existe "a sinergistic relationship between word and world"2 (KINCHELOE, 2008, p. 16).

El lenguaje empleado en el proceso de enseñanza opera en diversos sentidos y puede ser útil tanto para subyugar, como para reflexionar y cuestionar (SCHMIDT, 2005, p. 8).

El análisis de las interacciones adulto-niño es un aspecto central en la dinámica de aprendizaje en educación inicial. ¿Qué se espera de las interacciones en las aulas de educación inicial? Diversos autores reflexionan al respecto esperando que estas "sean afectivas y cognitivas, en instancias lúdicas y con significados propios de su etapa y de su ser singular" (PERALTA; HERNÁNDEZ, 2012, p. 14). Para otros autores "ese es el mayor desafío de la Educación Infantil" (KRAMER, 2013, p. 19). Asimismo se sostiene que "interacciones positivas y coherentes en los centros de educación inicial pueden llegar a compensar en parte las carencias del hogar y fomentar en los niños una mayor seguridad y confianza" (PANIAGUA, 2012, p. 22) lo cual también puede actuar en el sentido contrario, esto es, "si las interacciones que se plantean en el centro infantil son insuficientes o muy problemáticas pueden perjudicar a niños que incluso contaban de partida con un buen nivel de seguridad básica" (PANIAGUA, 2012, p. 22).

En resumen, las interacciones son un campo medular en la dinámica de aprendizaje en educación inicial. En ellas estriba el aseguramiento emocional requerido para el proceso de aprendizaje. En este sentido, junto con Didonet (2012), el presente estudio reivindica el derecho a una educación inicial emancipadora, que contribuya a la construcción de la identidad personal y colectiva, a la constitución de ciudadanos libres y responsables identificados con su historia y su cultura.

\section{“Canta, y cantar y cantar" ... las canciones como discursos}

Como sostiene Fairclough (1993), los discursos cuentan con un conjunto de elementos que rodean la producción, circulación, recepción, y consumo, de los mismos. 
Las canciones conforman un campo discursivo en tanto reúnen esta condición.

Las canciones constituyen actos comunicativos que promueven diversas interacciones, tanto en las docentes, como en los niños. Como refiere Mendívil (2014), "cantar implica participar de una serie de actos de habla, actos comunicativos, en los que se producen textos que interactúan en una práctica discursiva y en una práctica social específica". Desde las canciones más sencillas, hasta las más complejas, todas ellas trasmiten discursos que se reiteran y que construyen sentido.

El cantar canciones en grupo constituye una práctica social caracterizada por una serie de intercambios lingüísticos e interacciones corporales, en esa medida cumplen la función de discursos señalada por Calsamiglia \& Tusón (2008).

La palabra cantada crea una nueva forma discursiva, más perceptiva y sensible, una forma diferente de pensar, sentir y expresarse con el lenguaje, que redimensiona su función comunicativa. La voz, la palabra cantada y el gesto invitan a recrean una forma discursiva distinta "Todos estes elementos constituem uma forma. Uma forma de ver, de sentir de interpretar o texto e o mundo"3 (GROSSI, 2008, p. 154-155).

Al movilizar la interacción social, las canciones trascienden el significado lingüístico y se proyectan hacia la forma de entender la realidad social "Las canciones son un texto, son palabras y son un acto social. Sus mensajes son parte de la construcción del mundo y la construcción y autoconstrucción de sujetos sociales" (FERNÁNDEZ, 2005, p. 29). Por tanto, las canciones no son eventos desligados de un contexto, más bien representan discursos válidos que se enlazan con otros discursos que justifican una "lógica" social.

Si se asumen las canciones como discursos producidos en contextos reales, uno se remite no solo al proceso de producción, sino también al rol que juega en la comprensión de significados y a su impacto en los procesos de transformación social.

Cabe destacar que el lenguaje y los discursos no solo operan a nivel lingüístico, su efecto alcanza los campos identitarios. De este modo, las identidades se van construyendo en las canciones que se cantan, las que promueven procesos identificatorios que se van dando en función de determinados autores, intérpretes y personajes reales o ficticios que conforman el imaginario colectivo. De este modo, las identidades de docentes y alumnos progresivamente se modelan con las canciones.

Las canciones constituyen un tipo de discurso cuyos mensajes trascienden lo estrictamente "musical" o "lingüísticos". Las canciones se constituyen en discursos ideológicos, trasmitidos y consumidos por las personas en sociedad, a partir de los cuales se construye el concepto de realidad.

En relación a las implicancias ideológicas de este recurso educativo Fernández (2006) advierte que las canciones son un medio ideológico de reproducción o cambio social "que crea, recrea, reproduce, y a veces cambia el discurso hegemónico cultural de una sociedad dada en un momento determinado" (FERNANDEZ, 2005, p. 37). Asimismo, alerta que, en el caso particular de la canción infantil, su mensaje "se cuela entre los resquicios de la cultura popular y se reitera una y otra vez, insertándose en las células cerebrales desde la más tierna infancia, desde los arrullos y los juegos de corro" (FER- 


\section{NANDEZ, 2005 p. 67).}

En efecto el análisis de los discursos y mensajes de las canciones en la práctica educativa es una demanda que implica relacionar los discursos entre sí, tanto como a éstos con el contexto de producción que los genera. Urge por tanto interpretar las canciones como interacciones discursivas en contexto tratando de identificar las interacciones comunicativas que median la enseñanza de canciones; las fuentes que nutren los repertorios docentes; las voces representadas y las excluidas; los estilos de vida que se proponen; las relaciones de poder. Todo ello alimenta el perfil de las identidades infantiles y docentes que se construyen; así como la infancia que se construye y los protagonistas y actores de dicho proceso. En suma, se trata de develar lo que ocurre en las aulas, a fin de esclarecer los aprendizajes que efectivamente se dan alrededor de la canción.

En este sentido, el presente estudio concuerda con Fernández (2005), y Mendívil (2007), en el interés por develar el mundo oculto de las canciones infantiles. La singularidad del estudio reside en el análisis contextuado de una práctica pedagógica específica de alta recurrencia en las aulas de educación inicial.

Canciones e interacciones... la dinámica del poder docente

A continuación, se presenta la práctica discursiva en la que están inmersas las canciones y los procesos implicados en ella: producción, distribución y consumo. Como sostienen Calsamiglia y Tusón (2008), se trata de un análisis micro sociológico contextuado que incide en los roles de los agentes; tanto a nivel individual, como colectivo. En esta medida evidencia la efectividad ideológica de los discursos, tanto como de los sentidos compartidos.

En coherencia con el planteamiento de Fairclough (1993), los procesos de producción revelan los recursos disponibles de los participantes, las normas internalizadas, así como las convenciones para la producción, distribución y consumo de textos. En algunos casos, se retoman los textos para ser analizados desde el marco institucional. Del mismo modo, se analiza la intertextualidad a la luz de la coherencia, contradicción o ambivalencia entre estos. Otro aspecto que se considera es la interdiscursividad, viendo como esta funciona a nivel institucional a fin de ir enlazando sentidos aspecto de particular importancia en la medida que afecta la constitución subjetiva de las personas, y, por ende, la formación de sus procesos identitarios.

Como Hall (2003) sostiene, a través de la representación el lenguaje produce significado. Como acto humano, el lenguaje es relacional y aporta a la configuración de sistemas representacionales que se constituyen como prácticas culturales y lingüísticas de producción y circulación de significados los cuales se imbrican con el poder ejercido desde un contexto social, cultural, histórico y político (FOUCAULT, 1983). De allí la necesidad de analizar lo que se dice antes, durante y después de cantar una canción.

El nivel de coherencia discursiva se indaga a partir de fragmentos de las observaciones en clase, con ello se integra un primer análisis que relaciona la práctica discursiva a nivel institucional.

Al tratarse de un análisis a nivel micro sociológico se toma como referencia frag- 
mentos seleccionados de las interacciones los que han sido recogidos durante las observaciones de jornada completa realizadas en una institución educativa pública "típica" de educación inicial, la cual fue seleccionada al azar. El trabajo de campo se realizó en el año 2013. La institución educativa constaba de cuatro aulas de tres, cuatro y dos aulas de cinco años respectivamente. Las docentes de aula no eran profesoras especialistas en música, se trataba de docentes regulares que utilizaron las canciones como el recurso pedagógico por excelencia, realidad muy extendida en las instituciones educativas de educación inicial.

Las observaciones se realizaron en diferentes meses, días y en todas las aulas por igual hasta que por saturación, se concluyó con ellas. La institución educativa se encontraba ubicada en el distrito de San Juan de Lurigancho, distrito más poblado de Lima que acoge una amplia diversidad de migrantes de primera, y segunda generación.

Como análisis microsociológico se tiene el propósito de mostrar la cultura institucional a partir de la selección de diversos episodios representativos que articulan discursos hablados y cantados y dan coherencia a los hallazgos. El estudio no profundiza en el análisis melódico de las canciones, no obstante, es pertinente acotar que las canciones analizadas en su mayoría evidenciaron carencia de recursos melódicos y rítmicos.

A continuación se presentan cuatro episodios que corresponden a interacciones a partir de los discursos hablados y cantados que circulan al interior de cada una de las aulas de la institución materia del caso. De esta manera, todas las docentes y grupos de niños se ven representados por igual.

Por lo tanto, la selección de estos eventos o contenidos constituyen aspectos representativos de la ideología y cultura institucional. Para finalizar se elabora un análisis global que presenta relaciones entre los hallazgos.

\section{Una mirada al aula de tres años}

Las interacciones que se presentan fueron recogidas en el aula de tres años y muestran la dinámica de la docente, con los niños ${ }^{4}$.

Durante la primera visita a la institución la profesora del aula dio inicio a la sesión empezando a cantar la canción "A guardar"5. De modo reiterado, la docente advierte que si el grupo no realiza la acción pondrá la canción "Tres ositos melosos"6 .

Los niños se encontraban jugando pues era el inicio de la jornada. La profesora sin mediar introducción interrumpe el juego y empieza a cantar mientras motiva a los niños a ordenar el aula

\section{A guardar, a guardar, \\ Todo, todo en su lugar}

Luego D3 se dirige al grupo de niños y les pregunta ¿Ustedes son como los ositos?

\footnotetext{
4 La sigla D3 corresponde al testimonio de la docente del aula de tres años recogido en la bitácora del trabajo de campo. Los nombres han sido cambiados para proteger la confidencialidad de la información.

5 La canción "A guardar" forma parte de un repertorio compartido entre la mayoría de docentes de educación inicial.

6 "Tres ositos melosos" es una canción compuesta por Miss Rosi, cantante peruana, administradora de profesión, con formación instrumental en guitarra, compone música para niños la cual es ampliamente conocida por sus alianzas con diversas empresas.
} 
Los niños en coro responden iiiiNOOO!!!!

D3 insiste ¿Ustedes cómo van a dejar todo? Algunos niños responden: Ordenado...

D3 reitera Así quiero ver cada cosa en su... y los niños en coro completan la frase diciendo la palabra "LUGAR".

Como se aprecia la interrupción del juego constituye una agresión en tanto no se dio tiempo a que los niños se organicen para concluir el momento del juego. La agresión se inicia con la entonación de la canción "A guardar" mientras los diálogos de la docente aluden a otra canción "Tres ositos melosos". Durante las interacciones destaca la formación de sentidos a través de la recurrencia de la docente quien dice frases que son completadas por los niños.

D3 continúa: ¡En su lugar!!... muy bien ¿ya?... si no voy a poner la canción de los ositos? ¿Pongo la canción de los ositos? Los niños finalmente responden afirmativamente.

Aun cuando los niños ya aceptaron que la docente ponga la canción "Tres ositos melosos" la docente vuelve a reiterar la advertencia a través de una pregunta

D3: ¿Pongo la canción de los ositos para que ustedes se acuerden que tienen que ser ordenados?

Los niños siguen jugando haciendo caso omiso a la insistencia de la docente.

D3: Vamos a poner la canción de los ositos para que se acuerden que tienen que guardar...escuchen, escuchen la canción de los ositos.

Es entonces que D3 pone el disco compacto (CD). La canción no se escucha por el ruido que hacen los niños. La docente trata de llamar al orden, pero el ruido lo impide. En ese momento, D3 empieza a cantar, ningún niño la sigue, todos juegan. Mientras se escucha la canción ella se dirige a los niños.

D3: $i E s c u c h e n$ i iEscuchen! Lo que dice la canción de los ositos para que sean ordenados

D3 insiste poniendo el CD pero los niños continúan haciendo ruido. No se escucha nada. Ante esa situación la docente se da por vencida y apaga el CD.

Como se mencionó anteriormente, la sesión se inició con una agresión. Es comprensible la respuesta de los niños quienes muestran su resistencia a través de la desobediencia traducida en el ruido que hacen y la forma en que ignoran a la docente.

En esta primera parte de la sesión es posible constatar cómo la canción se emplea como un mecanismo de control simbólico del poder, esto se traduce en reiteración de D3 quien "amenaza" con poner la canción de los ositos. Los sentidos se van formando de modo complementario e interactivo: ella insiste en poner la canción de los ositos, mientras los niños se resisten a escucharla. Pero ¿Qué dice la canción "Tres ositos melosos"? ¿Por qué es tan importante para la docente que los niños la escuchen? ¿Por qué los niños muestran tanta resistencia a la misma?

Para comprender a continuación se transcribe el texto:

Tres ositos melosos perdieron sus baberos

y lloran por aquí, y lloran por allá

no quieren comer más.

Vino mamá osa, rebusca en los cajones

y lloran por aquí, y lloran por allá

no quieren comer más. 


$$
\begin{gathered}
\text { Vino papá oso, les jaló de las orejas } \\
\text { y lloran por aquí, y lloran por allá } \\
\text { no quieren comer más. }
\end{gathered}
$$

Los tres ositos melosos encontraron sus baberos

entre medias y zapatos revueltos y melosos

aprendieron la lección, ahora ordenados son.

Como se aprecia el uso de la canción "Tres ositos melosos" no es casual, más bien es posible establecer una relación de causalidad en tanto la canción representa la advertencia, así como también considera el comportamiento esperado y de no respetarlo, el castigo implícito, por lo menos a nivel simbólico. El juego de poder entre los mecanismos de control y los de resistencia son evidentes. La docente es quien pregunta, los niños responden de acuerdo a lo que ella espera, inclusive aceptan y hasta solicitan que se coloque la canción, no obstante, pese la insistencia de D3, los niños hacen caso omiso. Ante esta situación, D3 apaga el CD y empieza busca otros recursos para imponer el orden en el aula. El testimonio evidencia el carácter relacional en torno a la canción, y la agencia de la docente.

Pero la interacción en torno a dicha canción aún no concluye. Antes de finalizar la sesión D3 vuelve a colocar la canción "Tres ositos melosos", antes de hacerlo señala:

D3: ¡Párense al lado de la si-lla! Ya... vamos a cantar la canción del osito ¿ya?... ivamos a ver si han dejado ordenado!... a ver... como quiero yo... ¿o están como los ositos que perdieron todo?... a ver... D3 coloca el CD con la canción "Tres ositos melosos", canta y anima a los niños a cantar con ella.

En este corto diálogo se muestra la reiteración de una imposición. D3 se resiste a no dejar en claro que dicha canción tiene que ser escuchada. Ella centra la atención en su persona, empieza a cantar y los niños la siguen.

La frase inicial no constituye una pregunta sino una aseveración jvamos a poner la canción de los ositos! Se trata de una declaración, precedida de otra afirmación ivamos a ver si han dejado ordenado! la que supone la constatación de la tarea que deben realizar los niños, y verificar si todo queda ordenado. Luego se encadena con una tercera idea jcomo quiero yo...!. La cadena de sentidos enlaza el canto, con la constatación de orden, en función de lo que la autoridad demanda. De este modo, no queda la menor duda del mensaje: hay que hacer lo que pido, como yo lo pido. Por último, la pregunta final ¿o están como los ositos que perdieron todo? evidencia de modo directo la intención de la docente: lograr que los niños se identifiquen con los ositos. La canción describe una secuencia de hechos desafortunados: los ositos perdieron sus baberos, se asustaron, lloraron, vino su mamá rebuscó los cajones, luego vino el papá y les jaló de las orejas, y al final una moraleja: aprende a ser ordenado para que no te pase lo mismo que a los ositos, es decir, para que tu mamá no tenga que rebuscar en tus cajones, y tu papá te jale de las orejas.

Concluido el objetivo se reinicia el diálogo:

D3: A ver...¿Qué perdieron los ositos?. Los niños responden ¡SUS BABEROS!

D3: ¿Perdieron qué? Los niños reiteran: ¡sus baberos! 
D3: ¿Por qué no cuidan? Un niño responde: ...porque no ordenan

D3: Porque no ordenan ¿no?... y ¿Qué dijo mamá osa? ... Otro niño señala: intervienee...

D3: le jaló de las orejas... (afirmando) ¿Y los ositos encontraron sus baberos?...

Como puede inferirse, por un lado, se naturaliza el castigo físico como propio del contexto familiar. Las preguntas interpelan directamente a los niños. D3 no escatima esfuerzos en confirmar que el mensaje de la canción ha sido comprendido. Este hecho es sumamente delicado. En la realidad social peruana la violencia doméstica y la agresión a los niños constituye una lacra social difícil de desterrar. La naturalización del castigo físico por una figura de autoridad como es el caso de D3, lleva a perpetuar esta conducta que atenta contra los derechos del niño y que, en casos extremos, puede concluir en la muerte.

Luego de unos diálogos adicionales la actividad concluye con la canción "Todos sentaditos para irse" creada por la docente

Todos sentaditos, Todos sentaditos, todos sentaditos, Pa' que se puedan ir

Si no están dormidos, si no están dormidos, si no están dormidos, no se van a ir

Todos sentaditos, Todos sentaditos, todos sentaditos, Pa que se puedan ir Si no están dormidos, si no están dormidos,

Si no están dormidos, no se van a ir

Al imbricarse los diálogos, con las canciones "Tres ositos melosos" y "Todos sentaditos para irse" se revela la causalidad entre el comportamiento y la advertencia no solo de castigo físico, sino también de reclusión, fijando la figura de autoridad y el juego de poder. De este modo los sentidos discurren en una misma tendencia fortaleciéndose las cadenas semánticas.

El maltrato infantil en el ámbito familiar es una realidad cultural y una práctica social que aún está muy enquistada en el Perú. Se estima que a nivel nacional más de un tercio de la población practica el castigo físico como medio disciplinario. La violencia entre niños, como la violencia entre adultos y niños, configuran una situación de "violencia sistémica" en el ámbito escolar lo que coincide con los hallazgos realizados por Fernández (2005) que constatan la naturalización del castigo físico en las canciones infantiles.

De otro lado, también es posible analizar la concepción subestimada del niño a través del uso reiterado de preguntas convergentes a manera de interrogatorio con el propósito de corroborar la comprensión gradual y potenciar la efectividad ideológica de los discursos a nivel individual, tanto como colectivo. De este modo, como sostiene Foucault (1983), se revela la forma en que los discursos se yuxtaponen, y alinean con el saber y el poder.

También se aprecia la coherencia discursiva entre el discurso hablado, y los dis- 
cursos cantados los cuales están notoriamente orientados. Así, los discursos docentes se articulan con las canciones. La interdiscursividad, es decir coherencia entre los discursos institucionales, afirma los roles de quién manda y quién obedece y qué es lo que unos y otros deben hacer.

Este primer análisis evidencia que las identidades de docentes y alumnos son relacionales e interactivas. De un lado, se fortalece la docente con una identidad dominante y hasta amenazante, y de otro los niños con una identidad sumisa y dependiente. En este juego, las canciones intervienen afirmando dichas identidades y sentidos, así como las relaciones de poder.

De esta manera la formación identitaria se va gestando en un contexto de lucha simbólica entre los intereses de los niños y los de las docentes, y aun cuando ellas ostentan un poder, los niños poseen mecanismos de resistencia que los llevan a trasgresiones de diversa índole que en el caso concreto no se ven, pero que se abordarán más adelante.

Estudios previos realizados en el Perú reconocen la influencia del docente en el desarrollo identitario de los alumnos a su cargo: "cada una de las interacciones con sus alumnos, trasmite y refuerza valores que pueden fortalecer o no la identidad de los niños y niñas" (VÁSQUEZ DE VELASCO, 2012, p. 102). En este sentido ¿Es pertinente que los alumnos de educación inicial desarrollen identidades sumisas? ¿Es conveniente que los niños de educación inicial desarrollen identidades proclives a la amenaza y el castigo físico? Cabe entonces la pregunta ¿Es esta la educación que requieren los niños y el país?

Lo que ocurre en el aula de cuatro años

A continuación, se describe un ejemplo tomado del aula de cuatro años donde interaccionan la docente (D4) y los niños.

Luego de haber participado de la ceremonia de izamiento de bandera. Los niños ingresan al aula, rezan el Padre Nuestro y el Ave María y cantan las canciones "El amor de Dios", y "Palomita blanca, palomita azul"7. Cuyos textos se describe a continuación:

El amor de Dios es maravilloso

El amor de Dios es maravilloso

Grande es el amor de Dios

Tan alto que no puede ser más alto que Él

Tan bajo que no puede ser Más bajo que Él

Tan ancho que no puede ser

Más ancho que Él

¡Grande es el amor de Dios
Palomita blanca, palomita azul, Llévame en tus alas a ver a Jesús

Si mi niño bueno yo te llevaré

Porque en tu clase

¡Te has portado ¡Bien! 
Luego se inicia el siguiente diálogo:

D4: a ver... ya veremos... le hemos rezado a Diocito... le hemos cantado... ahora... una cancioncita de relajo ¿qué canción?". Sin mediar respuesta la docente empezó a cantar la canción "El pericotito8". Al concluirla ella se dirige al grupo de niños

D4: ¡MUY BIEN CHICOS!" BUENOS DÍAS! Los niños responden ¡BUENOS DÍAS!!!

En ese momento uno de los niños le pide la canción "El granito de mostaza"9. El niño grita insistentemente pidiendo la canción, la docente lo ignora.

D4: ¿Cómo han amanecido? Los niños responden entusiastamente ¡BIEEEEN! En el fondo se escucha la voz de otro niño que dice ¡MAL!

D4: (voltea y lo mira con cara de sorprendida) ¿POR QUÉ? El niño responde: Porque no he dormido...

D4: (dirigiéndose al grupo de niños) ... A ver... está hablando José Manuel... a ver dime ¿Por qué no has podido dormir?... Jose Manuel responde: ...yo no he podido dormir porque mi hermano me está molestando...

D4: ¿Le has dicho a tu papá y a tu mamá que te ha estado molestando? Jose Manual hace un gesto afirmativo con la cabeza

D4: A ver... YO les he dicho que para uno dormir bien... es que seguro no le han rezado a Diocito en la noche... ¿ahhh? ¡No le han rezado! (con voz firme y segura)

De modo similar al caso anterior se aprecia una secuencia de diálogos que desarrollan sentidos y significados al vincular las canciones, con las acciones, actitudes, roles y creencias sociales.

En primer lugar, la docente ostenta el poder de considerar o ignorar a los niños. Al inicio de la interacción ella consulta qué canción quieren cantar los niños, no obstante, ella decide cantar la canción "Un pericotito". Luego un niño le pide cantar la canción "El granito de mostaza", y aunque el niño se lo pida casi gritando ella lo ignora. De este modo el mensaje es claro: quien toma las decisiones de lo que se canta es la docente.

Es posible que la pregunta sea parte de un formalismo, lo concreto es que la docente no escucha el pedido del niño, porque no fue formulado como ella lo esperaba. De este modo, se afirma la identidad de la docente como la persona que no escucha a los niños si ellos no respetan el estilo comunicativo y condiciones señalados previamente por ella. Esta conducta responde a un patrón institucional. Las diversas docentes ignoran a los niños que gritan o hablan fuerte. De este modo ellas regulan, o tratan de regular, el volumen de la voz de los niños cuando se dirigen a ellas. No obstante, esta actitud contradice el pedido, reiterado a nivel institucional, de cantar fuerte porque "ellas no escuchan".

Asimismo, se observa que la docente establece relaciones de causalidad entre el mundo familiar, y las acciones que los niños realizan en la institución educativa. Las justificaciones instrumentales y su vinculación con los sistemas de creencias se relacionan constantemente creando sentidos. Nótese que las dos canciones entonadas al inicio de la interacción "El amor de Dios" y "Palomita blanca, palomita azul" afirman la importan-

8 Canción tradicional que forma parte del repertorio infantil latinoamericano.

$9 \quad$ Canción cristiana tradicional. 
cia de la religión y la religiosidad. De modo más específico, la canción "Palomita blanca, palomita azul" (32) que se entonó justo antes de esta interacción simboliza la recompensa frente al cumplimiento de un mandato divino reflejada en la frase "si, mi niño lindo yo te llevaré/ porque en tu clase te has portado bien". Así, tal como lo describió Fernández (2005), las canciones religiosas van creando mapas mentales sobre el ordenamiento social. Además de ello, la oración en esta interacción, representa un mecanismo de control simbólico que tiene su correlato con los premios y castigos de la vida cotidiana. La docente aparece, como la mediadora al ser quien enseña cómo agradar de Dios y pone de manifiesto el orden del discurso (FOUCAULT, 1983). La religión como una verdad indiscutible vinculada a un principio de control. De esta forma, se pone en evidencia las restricciones, se la vincula a rituales religiosos, mostrando la forma cómo se materializa el discurso.

De esta manera las canciones religiosas instruyen en la religión católica como un campo de regulaciones, más que como un sistema de creencias. Las acciones de la vida cotidiana guardan relación con las prácticas religiosas. Como refiere el testimonio, el mundo emocional de los niños es silenciado y minusvalorado, y la falta de escucha de los adultos es tomada como una acción natural, tanto al interior de la institución como a nivel familiar. Cada pregunta conduce a una respuesta grupal esperada, si la respuesta sale del esquema esta no es tomada en cuenta. Los conflictos surgen ante lo inesperado. El Niño1 expresó su malestar y fue desatendido, quedando esta desazón en un segundo plano. Lo delicado es que se deja al niño no sólo en situación de desamparo, sino de vulnerabilidad, o por lo menos, de incertidumbre.

Cabe preguntarse si con esta realidad será posible establecer un vínculo con la docente y en razón de ello ¿Qué resonancia pueden tener estas acciones en el establecimiento de la autoestima, el reconocimiento de la alteridad y en última instancia la formación identitaria? ¿Qué imagen de docente es la que estos niños construyen? ¿Qué imagen de alumno es la que la docente concibe?

\section{Y en uno de los salones de cinco años...}

En este caso se analiza una de las aulas de cinco años, representada por la docente (D5A).

Como se ha venido sosteniendo, la relación entre diálogos y canciones es una constante en los modos de comunicación al interior de la institución educativa estudiada. Esto puede apreciarse en el siguiente registro:

Los niños se alborotan, frente a ello la docente empieza a cantar

La lechuza, la lechuza ${ }^{10}$

Hace sh, hace sh

Todos calladitos,

todos calladitos

Hace sh, hace sh 
D5A: "... como ayer hemos hablado acerca de los animales...jEstéfano!... hoy día también vamos a continuar... vamos a conocer algo más de los animales... si conocemos lo vamos a recordar... lo vamos a recordar...¿ya?...jmuy bien!... a ver... yo voy a cantar una cancioncita... y ustedes van a ... ¡A VER!... yo quiero que ustedes estén atentos...que echen un candadito a su boquita... ¿YA?... un candadito jahí!... (señalando la boca) ¡Muy bien!... yo voy a cantar una canción ¿ya?... (empieza a cantar). Los niños no cantan, pero guardan silencio mientras ella entona la siguiente canción

Creciendo, creciendo, con mucho vigor

Yo me alimento, me alimento así

La vaca muy linda, la leche me da a mí

La gallina los huevos que me gustan más

La abeja muy linda la miel me da a mí

Para mi pancito y comer así

La oveja de sierra la lana me da a mí

Para mi chompita y abrigarme así

El pez muy grandote el atún me da a mí

Para mi comida y comer así Hmm! Hmmm! Hmmm ${ }^{11}$ !

D5A: “'A VER!... A ver... ¿qué he cantado?... a ver Daniel... ¿Qué he cantado chicos?... Daniel responde: la comida peruana...

D5A: ¿He cantado acerca de la comida peruana? Los niños responden: DE LOS ANIMALES!!!

D5A: ¡Ah...ya! tú estás en Mistura...de Gastón Acurio ${ }^{12}$...

N2: ...es que (la canción) dice... ATÚN!...

D5A: ¡Ah...ya! ...¿Qué más hablamos Melody?(dirigiéndose a Melody) Los niños responden: ...de los animales de la granja...

D5A: (palmada)... a ver ... Melody levantó la mano, yo no les voy a escuchar... no les voy a dar ningún premio... no les voy a dar nada... todititos hablan por aquí... aaaaaaaa (haciendo gestos y remedando a los niños). Daniel interviene: yo quiero dormir...

La exigencia de mantener la boca cerrada a través de diversos mecanismos a fin de prestar atención a lo que dice la maestra es un patrón reiterado a nivel institucional.

Como puede apreciarse hay una prevalencia de la voz docente la cual representa la voz de la autoridad. Como en los casos anteriores, las canciones guardan coherencia con las situaciones. En el presente caso, como respuesta a un contexto de desorden, la docente canta la canción "La lechuza" procurando influir en la conducta de los niños. De esta manera se reafirman los sentidos: los niños tienen que ser como la lechuza y quedarse callados o guardar silencio. De esta manera se perfila el silencio como un rasgo del alumno.

Al iniciar el diálogo D5A dice: "yo quiero que ustedes estén atentos...que echen un 
candadito a su boquita... ¿YA?... un candadito... jahí!... (Señalando la boca) ¡Muy bien!...", mediante esta frase la docente exterioriza su voluntad y aun cuando emplea diminutivos, no deja de ser una orden expresada y afirmada en dos lenguajes: el verbal y el gestual. De este modo, se reafirma el mensaje a partir de una secuencia que comparte una lógica: "todos calladitos como la lechuza" que reafirma el mensaje "echar candadito a su boquita", los cuales van acompañados de gestos.

Además, se constata la expresión del poder de la docente. Mientras el diálogo continúa, ella se dirige a Daniel, un niño especialmente cuestionador que se caracteriza por el enfrentamiento frontal y contestatario. La respuesta de Daniel manifiesta en" Yo quiero dormir", es trasgresora y evidencia su falta de interés en lo que la docente propone. Ante ello la docente emplea la burla como único recurso posible inicialmente frente a Daniel: "¡Ah...ya! tú estás en Mistura...de Gastón Acurio..."; para luego hacerlo extensivo al grupo de niños. "aaaaaa (haciendo gestos y remedando a los niños)". Con ello corrobora la falta de recursos para motivar al grupo y su incapacidad como figura de autoridad.

Poder y sumisión se muestran como una díada en los procesos de formación identitaria. De un lado la docente afirma su poder a través de distintos signos: palmadas, advertencias y burla. De otro lado se manifiesta la iniciativa, rebeldía y resistencia infantil a través de la expresión de Daniel que refiere su deseo de dormir, lo que representa negarse a realizar lo que la docente solicita. Ante ello, la docente se doblega, porque paradójicamente este es el niño más atento y en tanto ello, un niño líder del que todo el grupo está al pendiente y al que muchos siguen.

Advertencias, chantaje emocional, premios y castigos median las interacciones comunicativas "Yo no les voy a escuchar... no les voy a dar ningún premio... no les voy a dar nada". De modo semejante a los hallazgos de Mendívil (2010), la docente afirma su identidad como la proveedora por excelencia en todos los órdenes: es quien escucha, quien premia, fundando una amenaza de desamparo si los niños no cumplen con lo que ella solicita. Una vez más la relación entre saber y poder se hace evidente.

\section{Una mirada a la última aula de cinco años}

Esta es la última de las interacciones y corresponde a la segunda aula de cinco años. Recoge los testimonios de la docente (D5B)

La interacción se da inicio una vez que los niños regresaron del recreo y cantaron la canción "Si tú tienes muchas ganas" 13 la que ha constituido una válvula de escape para el grupo. La canción a la letra dice

Si tú tienes, si tú tienes, muchas ganas de (sentarte) ${ }^{14}$

No te quedes, no te quedes, con las ganas de (sentarte)

Si tú tienes, si tú tienes, muchas ganas de (aplaudir)

No te quedes, no te quedes, con las ganas de (aplaudir)

13 Esta canción es la versión en castellano de una canción infantil estadounidense llamada "If you are happy and you know it".

14 Van cambiando acciones reír, gritar, entre otras. 
Si tú tienes, si tú tienes, muchas ganas de (golpear la mesa)

No te quedes, no te quedes, con las ganas de(golpear la mesa)

Al finalizar la docente toma la palabra:

D5B: "¡Aplauso para ustedes!... ¡Aplauso para ustedes!... (mientras aplaude). Los niños alegremente responden ¡SIIIII!!!!

D5B: "Ahora... iSILENCIO!" En ese momento D5B empieza a cantar "Llamemos al silencio"15

\section{Llamemos al silencio, \\ Todos calladitos \\ que vamos a escuchar}

D5B: ¿Cada uno de ustedes sabe lo que es el silencio?

D5B: (susurrando) a ver... "la boquita bien...jCERRADA!... es momento de cerrar la boquita porque vamos a... DIALO-GAR!!!...vamos a CONVER-SAR...y también nos vamos a EX PRE...¿qué vamos a hacer? Un niño responde: ¡vamos a expresar!

En esta interacción es posible percibir la sucesiva contradicción de sentidos. El diálogo se inicia con una manifestación de felicitación, no obstante, asociado a este reconocimiento va la regulación que exige silencio al grupo con ello la docente rompe con una cadena de sentidos. En primer lugar, fruto de la canción "Si tú tienes muchas ganas" se había creado una atmósfera de libertad dado que la canción motivó la realización de diversas acciones como: llorar, dormir, zapatear, bailar, cantar, todas ellas motivadas por la docente. Todas estas acciones aparentemente resultaron divertidas tanto para los niños, como para la docente. Mientras los niños cantaban la docente se reía con ellos y los animaba a seguir la canción. Esta atmósfera compartida era coherente con las breves expresiones de aprobación y los aplausos, pero inmediatamente la docente interrumpe este clima e impone el silencio.

En realidad, lo que expresa esta situación, es que la docente sabe que tiene el poder de decidir los momentos de inicio y término de diversión del grupo. En este contexto, la canción no puede ser asumida como una expresión de los niños, sino como la expresión de la voluntad de la docente de conducir el comportamiento grupal esperado, lo que se reafirma con la pregunta "¿Cada uno de ustedes sabe lo que es el silencio?", frente a la cual ningún niño responde. Esta acción no es casual. Los niños perciben la intimidación y lo expresan respondiendo con la conducta esperada por la docente: guardando silencio. Luego viene una aclaración para reforzar sentidos y no quede la menor duda " $A$ ver... la boquita bien... ;CERRADA!... es momento de cerrar la boquita". Inclusive el hecho de decir la frase como un susurro atenúa el efecto de tensión creado, pero no lo elimina.

El contrasentido más claro se da en las frases siguientes al apelar a la boca cerrada como condición para el diálogo, la expresión y conversación. Inclusive el hecho no sólo de recalcar cada palabra, sino el de dividirla acentuando el énfasis, resulta intimidatorio. En este mismo sentido, la pregunta dirigida a una niña que no estaba prestando atención, crea una situación de zozobra.

Queda claro lo que realmente es significativo para la profesora: es más importan- 
te verificar si los niños entendieron su solicitud, antes que escuchar lo que realmente piensan. De esta manera, el pensamiento infantil es desvalorizado, un niño piensa en la medida que reproduce, repite y comprende el pensamiento de la docente. Así, se pone en evidencia lo sostenido por Foucault (1983), en el sentido de que la docente establece una clara relación entre saber y poder. Los niños aprenden que no se puede hablar de todo en la clase. La docente controla los discursos en el ámbito educativo. Como resultado, los niños aprenden a callar y a responder únicamente lo esperado por la figura que representa el poder. De este modo, los niños quedan excluidos al no satisfacer los requerimientos de la docente. Más aun, los niños construyen progresivamente identidades dependientes de la voluntad de otro, aprenden quién toma las decisiones, quién las sigue, quién o quiénes están calificados o descalificados para hablar.

\section{Reflexiones Finales}

Como se ha analizado, en el contexto institucional, las canciones son empleadas como herramientas de control simbólico, por tanto, este uso no es accesorio sino central en las relaciones entre docentes y niños, así como en la forma en que ambos construyen sus identidades al interior de la institución. La obediencia ciega es reiterada. Todo abona en la formación de sentidos y la construcción social de las identidades.

El inicio y término de cada una de las situaciones referidas resulta significativo. Son las docentes las que dan inicio a cada una de las interacciones, y son ellas quienes tienen la última palabra. Del mismo modo, a nivel institucional se encuentra coherencia interdiscursiva. Los discursos van entretejiendo sentidos compartidos que circulan al interior de la institución, sean estos hablados o cantados. Debido a ello, es posible sostener que a nivel institucional se crea una suerte de "sentido común" compartido.

Otros aspectos señalados por Coll \& Falsafi (2010) hacen referencia al desarrollo de la identidad del alumno a través de actos no-discursivos tales como gestos, posturas físicas, entre otros. Al respecto, se observó que el ejercicio del poder también se instala en el cuerpo. De esta manera "el cuerpo queda prendido en el interior de poderes muy ceñidos, que le imponen coacciones, interdicciones u obligaciones" (FOUCAULT, 1990, p. 83).

Durante el desarrollo de las sesiones, los niños deben permanecer sentados, en algunos casos se les pide que permanezcan con los brazos cruzados, la boca cerrada, entre otros. Todas estas canciones, como se refirió antes, se apoyan en canciones. De esta manera la identidad del niño como alumno pasa por un proceso de disciplinamiento corporal apoyado en canciones. El mismo hecho de ir todos juntos a los servicios higiénicos, comparte este propósito. Una vez más la efectividad ideológica de los discursos institucionales se potencia con ayuda de canciones.

De otro lado recogiendo el planteamiento de Coll \& Falsafi (2010); y Falsafi, Coll y Vadés (2010); y Andrew (2010); la identidad del estudiante se imbrica con la condición de aprendizaje manteniendo una relación de interdependencia. En las diversas observaciones se ha puesto de manifiesto el requerimiento de constante aprobación por parte de las docentes. Los niños permanentemente preguntan "¿Está bien?", “Así está bien?", “¿Con este color?" constituyéndose de esta manera en un patrón de aprendizaje. La do- 
cente es fuente de enseñanza y el niño recurre a ella en constante búsqueda de aprobación. Se consolida de este modo la díada saber y poder antes analizada en diversas canciones.

Si bien la identidad de alumno es una identidad situada, esta identidad se proyecta al medio social afectando el sistema de creencias, por tanto los calificativos son centrales no sólo para definir una identidad, sino también para proyectarla al espectro social más amplio.

El rasgo identitario que mayormente destaca es que el niño/alumno es uno en presencia de la docente (sumiso, dependiente...) y otro en ausencia de la misma (trasgresor, con iniciativa...) y esto no es casual. La concentración de saber y poder que reside en la docente reprime muchas de sus manifestaciones, por ello, los niños se expresan en libertad en ausencia de la docente.

Las interacciones al interior de la institución alumno-docente, alumno-alumno, alumno- personal auxiliar están mediadas por canciones, las que son empleadas de manera intencional por unos y otros, corroborando de esta manera el sentido compartido que tienen entre los diversos agentes educativos.

A diferencia de las docentes y el personal auxiliar, los niños asumen las canciones populares como propias. Ellos no hacen este deslinde entre "lo infantil" y "lo adulto". Por el contrario, la canción popular, y el baile que la acompaña, representan una válvula de escape al control adulto y en tal sentido, una oportunidad de liberación.

De este modo, se revela la canción como un referente institucional importante en la construcción social de la identidad del alumno.

Como corolario ha quedado demostrado las acciones de docentes y niños dan cuenta de cultura institucional que puede tener repercusiones tanto a nivel del desarrollo individual de los niños, como del desarrollo colectivo del grupo, así como también, en la constitución de las identidades profesionales en tanto estas establecen lo que es o no legítimo (SILVA, 2011, p. 214).

Como se ha constatado, en la institución educativa estudiada, la participación infantil es instrumental a los propósitos de las docentes. Los niños aprenden conductas dependientes de la voluntad docente. Aprenden a no tener iniciativa, a mantenerse en silencio, a agradar a las docentes, a depender en todos los sentidos; pero sobre todo aprenden que el sistema escolar es jerárquico, y tiene roles claros de quién ordena y quién obedece.

Estas son las identidades que de manera sostenida van desarrollando los estudiantes. Pero este aprendizaje no es exclusivo de los niños. Las docentes afirman su identidad mediante el ejercicio de permanente control sobre el grupo de niños, ellas aprenden a ingeniarse recursos para que les presten atención, y aprenden a pensar cada detalle de la acción educativa. Como resultado aprenden a centrar todo en ellas con el consiguiente abatimiento. De este modo, docentes y niños son producto de aprendizajes identitarios complementarios y muchas veces insatisfactorios para unos y otros. Por tanto, las identidades se gestan en un contexto conflictivo caracterizado por las relaciones de poder, las interacciones entre poder y saber, y la insatisfacción recíproca en los que la canción cobra centralidad.

De esta manera se evidencia como los testimonios revelan una percepción subes- 
timada de los niños, y de sus posibilidades de aprendizaje, así como un trato caracterizado por la descortesía y el trato anónimo, grupal y masivo, salvo cuando se requiera llamar la atención. Esto se refleja en la arbitraria toma de decisiones de las docentes, la repetición permanente de consignas, la frecuencia con que las docentes afirman sentidos haciendo que los niños completen palabras que ellas inician, respondan preguntas con respuestas que los niños ya conocen, entre otros aspectos. En todo ello subyace una concepción minusvalorada que asume al niño como un receptor de sentidos y no como productor de ellos.

En algunos casos se observa falta de respeto a las necesidades de los niños, e inclusive agresiones. A los niños no se les advierte el inicio o conclusión de una actividad. Simplemente cuando las docentes lo consideran necesario, interrumpen la actividad que los niños están realizando e irrumpen con una canción. Como se señaló anteriormente, esto constituye un tipo de agresión permanente en el que la canción juega un rol importante. Una educación que se precie de atender las necesidades de los niños debe orientar a los niños de modo que modo que estos puedan concluir las actividades que vienen desarrollando, evitando así que ellos se sientan violentados al verse forzados a terminar.

No es menos cierto que la iniciativa de algunos niños los lleva a asumir una posición de resistencia y, dentro de lo que les permiten sus recursos, aprenden a trasgredir el poder. En todo caso, aprenden que las relaciones con el poder son difíciles, y al no tener más recursos, se enfrentan o subyugan ante ellas. Esto, poco contribuye a la afirmación de una sana convivencia y un clima de paz social, no solo en el micro nivel, sino inclusive puede alcanzar repercusiones en el macro nivel.

En este contexto, los procesos de construcción identitaria se gestan en un clima conflictivo de lucha y resistencia, y con ello como sostiene Paniagua (2012), se puede perjudicar el nivel de seguridad básica. Esto es particularmente importante pues como se sabe, el nivel inicial, es el primer nivel del sistema educativo donde como sostiene Didonet (2012), el niño empieza a construir su ser niño, tanto como su ser de alumno.

Como el estudio ha demostrado, la canción tiene una función medular y a la vez instrumental. A través de las interacciones promovidas por las canciones en educación inicial, los niños van configurando qué y cómo es la dinámica del sistema educativo peruano en tanto este constituye el primer contacto.

Sería pretencioso asumir que los resultados puedan interpretarse al margen de los otros contextos con los que interactúa el niño. En realidad, los textos de las canciones entran en interacción con otros elementos intra y extracurriculares, dentro y fuera de la institución educativa y por supuesto del hogar. Las identidades de los diversos actores educativos se potencian y consolidan sentidos al entrar en relación con los otros elementos. Por lo tanto, no es posible afirmar que la canción en sí misma resulte determinante. Es la fuerza de la interacción con los discursos, y el contexto social más amplio, los que contribuyen a la formación de sentidos y significados. Lo que queda claro, es que de un lado las canciones en el contexto observado fueron utilizadas como mecanismo de control, y en tanto tal, perdieron su valor como expresiones culturales y estéticas. Por lo tanto, si la canción en educación inicial es el recurso pedagógico más usado por las, merece mayor estudio y atención. 


\section{Referencias}

ANDREW, P. La identidad y el aprendizaje: una perspectiva social. Multidisciplin@, Revista electrónica de la Facultad de Estudios Superiores Acatlán, n. 6 mayo-agosto 2010. Disponible en: <http://www.acatlan.unam.mx/multidisciplina/91/>. Acceso en: 23 sept. 2017.

BARTOLOMÉ, L. La pedagogía crítica y la educación de profesores y profesoras: radicalización del profesorado futuro. In: MC LAREN; KINCHELOE. Pedagogía Crítica ¿De qué hablamos? ¿Dónde estamos? Barcelona: Graó, 2008. p. 357-390.

CALSAMIGLIA, H.; TUSÓN, A. Las cosas del decir- Manual de análisis del discurso. Barcelona: Ariel S.A., 2008.

COLL, C. \& FALSAFI, L. Identidad y Educación. Revista de Educación, Madrid, Secretaría de Estado de Educación y Formación Profesional, Ministerio de Educación, n. 353, p.1727 sept./dic. 2010

DIDONET, V. Educación infantil en Perú y América: un desafío ante múltiples infancias. Educación, Lima, v. XXI, n. 40, p. 27-39, 2012.

FAIRCLOUGH, N. Discourse and social change. Cambridge: Polity Press, 1993.

FALSAFI, L. et al. Buenos estudiantes y aprendices competentes: la identidad de aprendiz como herramienta para la política y práctica. In: CONGRESO IBEROAMERICANO DE EDUCACIÓN - METAS 2021, sept. 2010, Buenos Aires. Anais... Buenos Aires, 2010. Disponible en: <http://www.chubut.edu.ar/descargas/secundaria/congreso/METAS2021/ RLE2221_Falsafi.pdf>. Acceso en: 30 sept. 2017

FERNÁNDEZ, A. Canción infantil: discurso y mensajes. Barcelona: Anthropos Editorial, 2005.

FERNANDEZ PONCELA, Anna M. Género y canción infantil. Política y cultura, México, n. 26, p. 35-68, enero 2006. Disponible en: <http://www.scielo.org.mx/scielo.php?scrip-

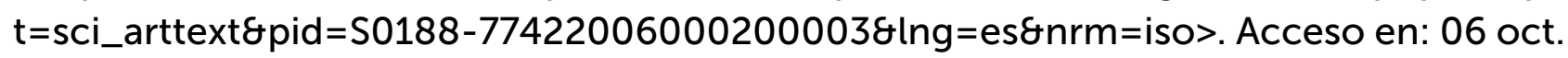
2017.

FOUCAULT, M. El discurso del poder. México D.F.: Folios Ediciones, 1983.

Vigilar y castigar - nacimiento de la prisión. Madrid: Siglo XXI, 1990.

FREIRE, P. Pedagogía del Oprimido. Lima: Universidad Nacional Mayor de San Marcos, 1971. 
GIROUX, H. Teorías de la reproducción y la resistencia en la nueva sociología de la educación: un análisis crítico. Cuadernos Políticos. México, D.F., n. 44, p. 36-65, jul./dic. 1985.

Introducción: Democracia, Educación y Política en la Pedagogía Crítica. In: MC LAREN; KINCHELOE. Pedagogía Crítica ¿De qué hablamos? ¿Dónde estamos? Barcelona: Graó, 2008. p. 17-22.

GROSSI, M. A. Literatura e informação estética: a oralidade pelas vias da poesia e da canção e seus usos na educação. (Tesis doctoral) - Faculdade de Educacao, Universidade de São Paulo, São Paulo, 2008. Disponible en: <http://www.teses.usp.br/teses/disponiveis/48/48134/tde-18022010-105123/>. Acceso en: 3 oct. 2017.

HALL, S. Representation: cultural representations and signifying practices. London: SAGE Publications, 2003.

KERTZ-WELZEL, A. Paradise Lost? A critical examination of idealistic philosophies of teaching through the lens of Theodor W. Adorno. Visions of Research in Music Education, n. 19, 2011. Disponible en: <http://wwwusr.rider.edu/vrme />. Acceso en: 2 oct. 2017.

KINCHELOE, J. Critical Pedagogy. New York: Peter Lang Publishing Inc., 2008.

KRAMER, S. Por una educación infantil de calidad. Nuevamérica, Rio de Janeiro, n. 138, p. 4-22, abr.-jun. 2013.

MC LAREN, P. Pedagogía, identidad y poder. Rosario: Homo Sapiens, 1998.

MC LAREN, P. \& KINCHELOE, J. Pedagogía Crítica ¿De qué hablamos? ¿Dónde estamos? Barcelona: Graó, 2008.

MENDíVIL, L. Lo que los niños cantan, comunican y aprenden. 2007. Tesis (Maestría en Comunicaciones) - Escuela de Graduados, Pontificia Universidad Católica del Perú, Lima, 2007.

Sentidos y Contrasentidos de las canciones. Una aproximación a la cultura infantil enseñada y aprendida desde ellas. In: II SEMINARIO NACIONAL DE INVESTIGACIÓN EDUCATIVA, 2010, Trujillo. Anais... 2-4 setiembre 2010. Disponible en: <http://siep. org.pe/archivos/up/121.doc>. Acceso en: 24 sept. 2017.

Interpretando canciones: discursos y construcción social de identidades en una escuela infantil en Lima. In: GARCÍA, I. El estudio del discurso en comunidades educativas: aproximaciones etnográficas. 2014. p. 171-180. Disponible en: <http://www. formule.com.es/wp-content/uploads/2014/05/El-estudio-del-discurso_G\%C2\%AAParejo-ed._2014.pdf>. Acceso en: 12 sept. 2017. 
PANIAGUA, G. El aporte de buenas interacciones en educación infantil. In: PERALTA, M. \& HERNÁNDEZ, L. Antología de experiencias de la educación inicial iberoamericana. Madrid: Ministerio de Asuntos Exteriores de cooperación AECID; BBVA, 2012. p. 21-37.

PERALTA, V.; HERNÁNDEZ, L. Antología de experiencias de la educación inicial iberoamericana. Madrid: OEl; UNICEF; Ministerio de Asuntos Exteriores de Cooperación AECID; BBVA, 2012.

REGELSKI, T. Critical theory as a foundation for critical thinking in music education. Vision of research in music education, v. 6, n. 1, enero 2005. Disponible en: <http://www-usr.rider.edu/ vrme/v6n1/visions/Regelski\%20Critical\%20Theory\%20as\%20a\%20Foundation.pdf>. Acceso en: 05 oct. 2017

SCHMIDT, P. Music education as transformative practice: Creating new frameworks for learning music through a Freirian perspective. Visions of Research in Music Education, v. 6, n. 1, enero 2005. Disponible en: <http://www-usr.rider.edu/ vrme/v6n1/visions/Schmidt\%20Music\%20Education\%20as\%20Transformative\%20Practice.pdf>. Acceso en: 27 sept. 2017.

SILVA, Joyce Mary Adam de Paula e. A construção da identidade de diretores: discurso oficial e prática. Educação em Revista, Belo Horizonte , v. 27, n. 3, p. 211-230, dic. 2011. Disponible en: <http://www.scielo.br/scielo.php?script=sci_arttext\&pi$\mathrm{d}=\mathrm{S} 0102-469820110003000118 \mathrm{lng}=\mathrm{en} \& \mathrm{nrm}=$ iso $>$. Acceso en: 06 oct. 2017. DOI: http://dx.doi.org/10.1590/S0102-46982011000300011.

STEINBERG, S. ¿De qué hablamos? ¿Dónde estamos? In: MC LAREN; KINCHLOE. Pedagogía Crítica ¿De qué hablamos? ¿Dónde estamos? Barcelona: Graó, 2008. p. 13-15.

VÁSQUEZ DE VELASCO, C. Docentes en protección de niñas y niños. Lima: SUMBI-Save the children, 2012. 